\title{
Agroecologia no Brasil: história e polissemia de um conceito
}

Paulo Henrique Vailati, Miguel Mundstock Xavier de Carvalho

https://doi.org/10.4322/mp.978-65-991393-9-0.c3

\section{Resumo}

As defesas entusiasmadas da Agroecologia no Brasil que podem ser ouvidas nos Congressos despertam uma sensação de esperança e preocupação. Esperança por que a agricultura precisa de soluções para alcançar um desenvolvimento mais sustentável, tornando-se menos invasiva ao meio natural, e que ao mesmo tempo atenda as questões sociais. Por outro lado, desperta também preocupação, pois fica claro que a polissemia do conceito gera possibilidades de interpretação inviáveis sobre essa prática de agricultura, que pode ser apreendida também como um movimento social e um ramo da ciência. Ao mesmo tempo, o conceito vem passando por uma considerável transformação ao longo das décadas, de uma maneira que as gerações mais novas mal percebem. Desde os excessos e questionamentos da contracultura, a agroecologia no Brasil vai encontrar sua origem em uma variada gama de influências do pensamento agronômico e ecológico, com aproximações e distanciamentos de movimentos esotéricos, ONGs e mais recentemente se institucionalizando na academia e nos Programas de Pós-Graduação. Nesse sentido, a proposta desse capítulo é explorar as polissemias que comportam o termo Agroecologia, com especial ênfase na evolução histórica, procurando compreender as transformações e os contextos sociais associados, elucidando as metamorfoses do conceito e como podemos imaginar o futuro na busca por uma agricultura mais sustentável.

Palavras-chave: agriculturas alternativas, conceito de agroecologia, contexto social da agroecologia, história da agroecologia no Brasil. 


\section{Introdução}

Embora o termo Agroecologia tenha origens na década de 1920 e que por sua vez a definição tenha proveniência no termo Ecologia no século XIX, o que se costuma entender por Agroecologia no Brasil hoje tem origens nas agriculturas alternativas da década de 1970. Nessa época florescia no país um movimento contracultural e ecológico, com suas exuberâncias, exageros e esperanças de fazer diferente, associado a um contexto de expansão do ensino universitário e de uma modernização agrícola. Assim como o movimento ecológico, o movimento agroecológico bebeu de diferentes fontes e influências de pensamento, e portanto se caracteriza por uma grande diversidade de percepções, unidas pela intenção de contribuir, por diferentes vias, para uma agricultura com menor agressão à natureza [1,2]. O presente capítulo procura apontar algumas discussões relevantes para o entendimento da história da Agroecologia no Brasil, como as aproximações das agriculturas alternativas das décadas de 1970 e 1980 com correntes esotéricas de pensamento, sobre o alternativo como parte do científico, sobre a Agroecologia ser uma "nova" ciência e, por fim, uma interpretação sobre como influentes instituições recentes, como a ABA (Associação Brasileira de Agroecologia), interpretam a Agroecologia na sua dimensão científica e também como parte de um movimento social e de uma prática agrícola.

\section{Agriculturas alternativas e correntes esotéricas de pensamento}

Em pesquisas realizadas na Hemeroteca Digital do site da Biblioteca Nacional [3], durante as décadas de 1970 até 1990 no Brasil, os termos agroecologia, agricultura alternativa e agricultura orgânica por vezes se misturavam nos periódicos com uma miríade de outros vocábulos considerados fantasiosos ou pouco estudados pela ciência, aguçando a mente de muitos para campos que se fundiam ao esoterismo e, dessa forma, acabavam por se distanciar das convenções científicas da época. Ufologia, Iridologia, Tarô, Gestalt, Psicologia Extra-Sensorial e Profecias e Apocalipse são alguns dos temas de palestrantes que dividiam a semana de apresentação com temas de Ecologia de outros dias, como Comunidades Rurais, Horticultura Urbana, Habitações Indígenas e Política Ecológica, em evento de cultura alternativa na cidade de Brasília, em 1983 [4]. 
Muitas das fontes da mesma época citavam, em contrapartida, matérias, entrevistas, transcrições de mesas redondas e propagandas de congressos e outros eventos com caracterizações mais científicas [5] voltadas a políticas públicas municipais [6], como por exemplo, a indicação da agroecologia ou de agriculturas alternativas para usinas de beneficiamento de lixo; como redução de custos agropecuários para pequenos produtores e para a agricultura familiar [7]; na forma de sistemas agrícolas voltados a países em desenvolvimento; para pequenas comunidades; para o interesse de assentamentos [8]; como projetos municipais de emprego para moradores de rua; como medida de preservação ao meio ambiente; no sentido de ampliar a autonomia do produtor brasileiro [9], a fim de desenvolver uma agricultura sem marginalização, dentre outros.

Em uma das pesquisas - datando de 1991 no jornal paranaense Correio de Notícias - consta matéria acerca de um projeto do banco Banestado que, com auxílio da então Empresa Paranaense de Assistência Rural (Emater/PR) desenvolveu o Programa Terra Viva, com fins de liberação de financiamento aos interessados em investir na área de agricultura alternativa [10].

Com base nessas informações variadas, discutíveis, e muito presentes em periódicos das décadas citadas, surge uma dúvida: por que o esoterismo integrava parte do meio de estudos das agriculturas alternativas?

Precisamos levar em conta duas informações precedentes à resolução da pergunta. A primeira diz respeito à historicidade dos conceitos, a qual preconiza que um mesmo conceito, analisado a partir de épocas ou regiões distintas, pode ter mais do que um significado, conforme visto nas descrições acerca do trabalho de Reinhart Koselleck [11]. A segunda se refere às mentalidades, aliada aos processos culturais que uma sociedade desenvolve e transforma e, com base nisso, aceita ou não ideias diferentes das suas, de forma a estigmatizar ideias distintas, absorvendo-as relutantemente ou até mesmo as demonizando [12]. Tomando como referência essas duas informações, compreendemos melhor como os vocábulos "alternativo" e "esotérico" puderam se unir na história da agroecologia brasileira, quando da análise das práticas agrícolas que seguiam caminhos distintos aos da agricultura convencional. 
Em uma busca no acervo da Hemeroteca Digital, realizada utilizando o termo "Agricultura Orgânica" no período entre 1970 e 1979, foram encontradas 28 ocorrências, em meio a 203 periódicos totais da década mencionada. A primeira dessas ocorrências, por exemplo, se intitula "Os Novos Alquimistas" no Jornal do Brasil (RJ), e trata do desenvolvimento de uma matéria cuja página inicial fala sobre as chamadas "Arcas", as quais são residências estrategicamente planejadas, com estufas e painéis de células fotovoltaicas que sustentam plantas produzidas com base na agricultura orgânica, e onde seus moradores tentam se desvincular do maquinário e das tecnologias mais agressivas à natureza, na época, buscando uma integração mais natural, por assim dizer, com o meio [13].

Assim, vemos que o despontar das agriculturas alternativas acabou sendo vinculado às filosofias de grupos espiritualistas ou a temas paralelos que mexiam com o imaginário popular, tornando muito mais socialmente apropriado acreditar em uma agricultura cientificamente comercializada e propagada massivamente na mídia, do que em outra que a contestava e era formada por, estereotipicamente, hippies da classe média.

Há de se considerar a complexidade do assunto como um todo: não se defende aqui a ideia de que os movimentos de origem da agroecologia, da agricultura orgânica e outros meios alternativos tivessem necessitado de atribuições religiosas, morais, espirituais, esotéricas ou da crendice popular. Em alguns casos a caricatura esotérica servia para descredibilizar uma abordagem agrícola, mas em outros casos, os grupos mesmos buscavam essa identidade espiritualista, como é o movimento da Agricultura Biodinâmica ou a própria agricultura orgânica de base cristã do início do século XX nos EUA [14]. Essas considerações ajudam a explicar por que em alguns casos ainda hoje algumas pessoas ligadas a Agroecologia tenham uma inclinação para as correntes esotéricas, o que despertou críticas sobre a seriedade e falta de rigor científico da Agroecologia por intelectuais como Zander Navarro, por exemplo [15].

\section{O que é "alternativo" é "científico"?}

Um dos livros de ciência mais indicado para estudos acadêmicos é "A estrutura das revoluções científicas", do físico e filósofo estadunidense Thomas 
Samuel Kuhn [16]. Sendo considerada uma obra visionária no que diz respeito ao entendimento da ciência e de como suas estruturas operam, essa Magnum opus de Kuhn ainda assim é muito criticada e não aponta referências que indicam um caminho para uma possível verdade metodológica ou que, minimamente, demonstram uma exatidão do processo de pesquisa e investigação como um todo. E este, ao contrário do que parece se supor, é um fator relevante e importante no processo de apreensão do trabalho da ciência, sob perspectiva dialética. Como o próprio título demonstra, sua teoria indicava que a ciência é determinada por paradigmas, e paradigmas são mutáveis. Por isso das "revoluções" no processo dialético do conhecimento, apesar de alguns pesquisadores discordarem de Kuhn - como o cientista cognitivo Steven Pinker - quanto a isso [17]. Dessa forma, existiriam padrões de pesquisa específicos para cada momento, quando então esses modelos seriam suplantados por novas descobertas, sendo estas, frutos de um processo que geraria uma nova revolução científica, como podemos averiguar no que diz respeito ao entendimento da História da astronomia e dos estudos cosmológicos [18].

A ciência seria justamente esse processo confuso, sendo sensata e confiável justamente por admitir suas redescobertas e equívocos, mesmo que dentro de compreensões distintas sobre uma determina análise.

Sob outra perspectiva e de maneira a realizar uma análise mais diretiva, tal qual ficou conhecida como racionalismo crítico, o filósofo austro britânico Karl Raimund Popper exemplifica, em sua obra "A lógica da pesquisa científica", que quaisquer teorias existentes na abrangência das ciências empíricas nunca poderão ser provadas em suas verdades, mas sim nas suas falsidades, também denominadas falsificabilidades ou falseabilidades, querendo dizer que é mais conveniente encontrar provas de que a teoria é falsa, do que insistir na tentativa de provar que a teoria em questão seja uma verdade [19].

Em meio a um processo de pesquisas científicas que utilizam um método dedutivo hipotético a indicar que toda ciência é conjectural, Popper traça um caminho distante do comumente estabelecido método indutivo, inferindo que, quanto mais testes e corroborações uma teoria adquire, mais ampla a próxima gama de testes deve ser, a fim de manter o que já foi corroborado até o momento e, para além disso, vencer os testes seguintes com níveis mais altos 
de universalidade [20]. Assim como Steven Pinker discorda de muitas das apreensões elaboradas por Thomas Kuhn em sua obra clássica, o filósofo da ciência Paul Karl Feyerabend discorda veementemente desta perspectiva de racionalismo crítico de Popper [21].

Feyerabend desponta como um exemplo claramente avesso às teorias de Karl Popper, se aproximando mais com o pensamento de Thomas Kuhn mas, mesmo assim, tendo suas particularidades de ideias quando do processo em que critica o excesso de razão sobre os métodos científicos e, justamente por isso, acaba sendo considerado por alguns como uma espécie de anarquista da ciência.

Feyerabend indica que a ciência não poderia se fechar em um conceito restrito que seguisse metodologias tão estreitamente delineadoras como as que convencionalmente buscamos seguir na atualidade. A ciência também pode ser feita por não cientistas e, quando cientistas profissionalmente estabelecidos, determinadas teorias científicas podem ser refutadas por métodos e atitudes mais amplas e não convencionais, que ultrapassam a esfera do que se conhece por razão.

Cientistas são como arquitetos que constroem edifícios de diferentes tamanhos e diferentes formas, que podem ser avaliados somente depois do evento, isto é, só depois de terem concluído sua estrutura. Talvez ela fique em pé, talvez desabe ninguém sabe [22].

Em síntese, Paul Feyerabend é a favor da ciência como inovação humana, mas é contrário às instituições e indivíduos que a utilizam para a propagação de suas próprias ideologias e, inclusive, como um meio para se obter pressão política. Toda regra científica pode ser violada a qualquer momento, o que implica na necessidade de condição de uma ciência "para todos", que não seja dominada nem por áreas como a sociologia, nem por métodos como os de modelo mais restritivo.

Essas três visões sobre possíveis revoluções repentinas ou transições suaves na ciência e o que se pensa sobre a mesma em um nível epistemológico se aproximam muito da composição dialética existente sobre a 
agroecologia no Brasil, em que alguns autores tratam do tema ora como um processo que poderá alterar drasticamente o entendimento do que é a agricultura, ora como transição que aos poucos será incorporada aos processos agrícolas já existentes, sendo que a identificação de uma agroecologia como ciência ou como parte desta acabou tornando-se também campo vasto de discussões.

Considerando o que foi exposto acerca da filosofia e história da ciência e agregando a esse pensamento o entendimento de complexidade que se tem sobre a concepção científica da agroecologia, observa-se que, para ambos os casos, faz-se necessária uma representação conceitual que guie o diálogo para um mesmo caminho.

As concepções estruturais sobre ser a agroecologia um movimento social ou uma prática agrícola, um processo de revolução científica com rupturas ou de transição com incorporações graduais para a agricultura mundial ainda podem existir e é até bom que existam, pois é sobre essa contestação, essa dialética e essas leituras paradigmáticas que a ciência costuma realizar as suas atividades. O problema talvez se inicie com maior predisposição à confusão, quando a metodologia e os processos do rigor científico escapam ao que se compreende como oficiais ou como comuns, na atualidade, e isso parece ocorrer em alguns casos. Como exemplo, podemos mencionar a homeopatia, que está presente nas agriculturas alternativas (e também na agricultura convencional) ou em atividades paralelas a elas, há décadas.

Produtos homeopáticos parecem ser amplamente utilizados como recursos efetivos na agricultura e na pecuária alternativas. Em uma das buscas de pesquisa utilizando a expressão "agricultura alternativa" foi encontrada uma matéria do jornal Correio de Notícias (Paraná) que, em edição de 1985, discorria sobre o $1^{\circ}$ Encontro Municipal de Agricultura Alternativa e Homeopatia Animal, com cerca de 200 agricultores das regiões de Lapa e Contenda [23]. O evento, conforme consta no periódico, foi promovido pela antiga Acarpa/Emater, e é um mero exemplo da década de 1980 no Brasil, em meio a uma homeopatia que surgiu já na Alemanha do século XVIII, e chegou ao território brasileiro, como prática, no século XIX.

Em entrevista, a professora Irene Maria Cardoso comentou acerca da homeopatia do solo, algo muito recente na história do Brasil e desenvolvida 
provavelmente por agricultores da região da Zona da Mata Mineira. Posteriormente, as práticas desses agricultores foram absorvidas por pesquisadores da Universidade Federal de Viçosa (UFV) e, conforme cita a entrevistada, o professor Vicente Wagner Casali se tornou um dos principais a sistematizar os experimentos homeopáticos na agricultura, em laboratório [24].

Mesmo sendo um tema ainda controverso para o público em geral e desacreditado por grande parte dos cientistas e pelas pesquisas bem conduzidas, as quais referenciam o homeopático como um método terapêutico, e mesmo muitas vezes considerando este método ou especialização médica como sendo pseudocientífico, a agropecuária convencional também tem se valido desses produtos para alguns de seus estudos e relações comerciais, aproximando-se dos modelos alternativos de décadas passadas [25].

A análise sob enfoque de duas questões que caberiam neste ponto da pesquisa talvez fosse: 1) a agroecologia está ganhando espaço e se comprovando como validada para seu emprego em meio à comunidade científica geral? Ou 2) a agricultura convencional está se apropriando de tecnologias e sistematizações aceitas pesquisadas na agroecologia para conseguir manter a continuidade de sua superioridade como mais influente e financiada na indústria e na política?

É este um exemplo, portanto, de uma das dificuldades pelas quais a ciência agroecológica passa no que diz respeito ao que é alternativo e o que é científico, e se o primeiro poderia integrar o campo do segundo.

Como segundo exemplo complexo da interação do alternativo com o científico, temos a Agricultura Biodinâmica. De acordo com o site da Associação Biodinâmica, antigo "Centro Demeter", as técnicas com compostos biodinâmicos

foram preparados por Rudolf Steiner, com base na Antroposofia, antes e durante o Curso Agrícola de 1924. Steiner afirma que "adubar consiste em vivificar a Terra" e com base nesta afirmação traz os preparados como sendo mediadores entre a Terra e o Cosmo [26]. 
Esses preparados podem ser considerados em alguns aspectos semelhantes aos homeopáticos, a considerar suas composições naturais e os métodos de fabricação e manejo descritos anteriormente, mas não são determinados pela teoria e prática da homeopatia médica citada. O nome biodinâmico indica que a atuação dos compostos, assim como no caso da homeopatia, se faz por meio de forças dinâmicas, e não da química nas suas composições. Alguns dos compostos indicam em suas descrições de funcionamento essa relação de forças cósmicas atuando conjuntamente ou predominantemente, apesar de muitos preparados conterem em suas misturas várias substâncias com atuação de ordem biológica, física e química, como esterco, casca de carvalho, chorume, biofertilizantes e outros, que agem em processos de fermentação e decomposição. Um dos preparados é o "chifresílica", indicado no texto da Associação com o código numérico "501", e conhecido como "preparado da Luz". De acordo com o excerto explicativo, ele atua "trazendo forças da periferia cósmica e intensificando a atuação da luz solar". A explicação não validada pela ciência se apresenta quando ocorrem nas assertivas da Agricultura Biodinâmica os vocábulos antroposofia, periferia cósmica e, assim como no caso da homeopatia, determina que os resultados positivos dos experimentos são conferidos por forças dinâmicas (do Cosmo), e não necessariamente por reações químicas (do solo e dos próprios compostos).

Com base nas definições sobre a ciência, nas descrições sobre os métodos alternativos apresentados, e nas situações em que se tentou correlacionar um e outro para o entendimento da questão "o que é alternativo é científico?", observou-se que há uma desarmonia no que diz respeito às concepções modernas sobre o que é científico e o que se demonstrou como alternativo nesta análise, caso da homeopatia e de algumas práticas da Agricultura Biodinâmica.

\section{Agroecologia como ciência, movimento social e prática agrícola.}

Em se tratando de agroecologia e de sua origem terminológica próxima ao ano 1930, a interdisciplinaridade se tornou consideravelmente importante na pesquisa para o entendimento do que seria esse alcance tão abrangente da área, que a considera como holística. As variações das esferas de estudos, 
abrangências de conceitos, formas de percepção e vivência da agroecologia são inúmeras, e ainda se alteram conforme os países em que estão inseridas, o que justifica a importância de vários olhares sobre ela. Existem distinções peculiares em países como Alemanha, EUA, França e Brasil, em que alguns deles despendem mais estudos à pesquisa laboratorial enquanto outros dão mais sentido social e cultural aos grupos promotores da expansão da agroecologia nas comunidades [27].

Ao determinar referências advindas de pesquisadores da área, também se torna possível a identificação de uma gama de distinções como, por exemplo, a que norteia o entendimento do Engenheiro Agrônomo, Prof. Dr. Carlos Armênio Khatounian (ESALQ- SP), o qual discorda da afirmação de que a agroecologia seria uma nova ciência, justificando que

Se a agroecologia é uma nova ciência então eu não preciso estudar agronomia. (...) Ele [o estudante] precisa conhecer ciência do solo; ele precisa conhecer fisiologia vegetal; ele precisa conhecer entomologia; ele precisa conhecer fitopatologia. Tudo isso são áreas do conhecimento que acabam ficando incluídas na velha agronomia, mas se eu vou aprender a nova, eu não preciso aprender isso [28].

Enquanto o Prof. Khatounian referencia a agroecologia como uma abrangência da ciência agrícola possuidora de um foco mais técnico e biológico, o Engenheiro Agrônomo, Prof. Dr. Manoel Baltasar Baptista da Costa (UNIARA-SP) passa a indicá-la como ciência que leva em conta a questão social, além do técnico e do biológico, afirmando que

...nós estamos em um impasse ecológico, social e produtivo na agronomia. (...) Hoje as universidades estão começando a ter uma abertura pra ver essa dimensão, principalmente social e ecológica da agricultura. Na ciência convencional tem muita coisa que é de interesse comercial. (...) A agroecologia é uma coisa mais independente (...) que não tem vínculo com o capital [29]. 
O Prof. Baltasar resume suas considerações com o seguinte problema: como se fazer uma agricultura sem exclusão social?

Todavia, cabe salientar que os termos "ciência", "movimento" e "prática" apresentados em conjunto com referência ao termo "agroecologia" aparentemente têm aumentado em um grande número de artigos nos últimos dez anos, desde o período aproximado em que Alexander Wezel et al publicaram um influente artigo, intitulado Agroecology as a science, a movement and a practice: a review.

No artigo em questão, analisa-se o surgimento do termo agroecologia, e como a partir disso ocorreram reinterpretações e ressignificações ao longo do tempo. Sobre essas confusões, reinterpretações e reconsiderações, Wezel et al realizam uma leitura separada e por regiões, partindo individualmente de cada uma das dimensões citadas no título de seu artigo. Nessa passagem do tempo, de 1928 a aproximadamente 1970 a agroecologia continuou com a definição majoritária de "ciência" ou "disciplina científica", mas foi a partir da década de 70 em questão que ela gradualmente foi emergindo como movimento (muito possivelmente em resposta direta à Revolução Verde e ao movimento ecológico) e, próximo da década de 1980, começou a se configurar como um conjunto de práticas agrícolas [30].

Sendo uma disciplina científica de início e a considerar que possui métodos holísticos e atribuições interdisciplinares, era comum que ocorressem ramificações em suas formas de apreender conteúdos afins. Do seu foco em agricultura ecológica com uma abordagem sobre o campo, promoveu-se posteriormente o novo foco sobre o meio ambiente e a sustentabilidade, levando em um terceiro ponto ao estudo de técnicas para o desenvolvimento dos dois primeiros focos. Um dos exemplos brasileiros atuais é o próprio Programa de Pós-Graduação em Agroecologia e Desenvolvimento Rural Sustentável da Universidade Federal da Fronteira Sul (Campus Laranjeiras do Sul - PR), a qual atribui em um mesmo nome de seu curso, as alcunhas históricas de disciplina científica de 1928-1970 e de incorporação da sustentabilidade.

A partir de 1990 o campo da pesquisa em agroecologia começou a se expandir consideravelmente, de acordo com os autores citados. É nesta mesma década que ela começa a despontar como programas oficiais de 
universidades, e não apenas disciplinas ou subdisciplinas de cursos. Mas ainda com dificuldades para se legitimar, talvez devido a ausência de enfoque estatístico em muitos experimentos, o que dificulta a publicação de artigos em revistas com maior fator de impacto. No caso do artigo de Wezel et al, citamse universidades dos EUA e da Europa. No Brasil em período posterior, poderíamos citar, por exemplo, o curso Técnico em Agroecologia da Escola Vinte e Cinco de Maio em Fraiburgo (SC) de 2005, e o curso Superior de Tecnologia em Agroecologia da Universidade Federal do Paraná (UFPR), de 2008 [31].

Além disso, houve um avanço nas políticas públicas no que diz respeito ao enfoque agroecológico quando do projeto da Política Nacional de Agroecologia e Produção Orgânica, política que propeliria o desenvolvimento de novos cursos e disciplinas [32].

Esse leque com definições de ciência, movimento e prática, levando a definições iniciais de ciência e alcançando a política governamental, tornou a agroecologia uma área que, sob análise da História Ambiental, pode ser vista entre o agroecossistema do campo até, posteriormente, os sistemas alimentares globais. Ou seja, podemos observar uma conexão entre áreas antagônicas ou mesmo paralelas de estudo, conforme mencionado no que diz respeito ao seu caráter holístico e interdisciplinar.

Abrindo possibilidades interdisciplinares para essas três interpretações, sendo ela um campo ainda em desenvolvimento e sabendo que ela continua a se expandir - por vezes ramificada em conceitos ou termos diferentes dos originais - acredita-se que a agroecologia possa se identificar, com base no problema apresentado neste capítulo, como uma ciência ou uma abrangência da ciência agrícola que serve de infraestrutura a inúmeros estudos acerca das transformações ambientais que podemos observar no mundo atual.

O alimento é algo imprescindível à sobrevivência do ser humano e, sendo assim, a agroecologia favorece a abertura de pesquisa sobre tudo o que concerne à produção, distribuição, conservação, comercialização e identificação desses alimentos, estando apta a responder questões múltiplas em relação a economia, às políticas públicas, ao desenvolvimento tecnológico, ao entendimento da vida cultural da agricultura familiar, aos processos biológicos de controle natural em policultivos, ao estudo técnico sobre 
produção orgânica, às relações entrópicas energéticas para o alcance de níveis sustentáveis, à química no que concerne ao melhoramento de plantas vinculada a uma preservação da agrobiodiversidade e estudos específicos das propriedades de cada solo, à engenharia e agronomia no que diz respeito aos agroecossistemas e seus desenhos, às relações humanas no que concerne aos diálogos sobre o desenvolvimento rural e os respectivos caminhos a serem trilhados, dentre outros, levando-se em conta locais, costumes, história de cada país, assim como a natureza específica de cada região e suas interações ecológicas características.

Dessa forma, fica clara a importância da compreensão sobre a agroecologia ser uma ciência que recebe contribuições de várias áreas do conhecimento, desde as ciências humanas até as ciências naturais, incluindo nestas as ciências básicas e aplicadas [33].

\section{A Agroecologia no período histórico mais recente: IBA, ABA, CBA, AS- PTA, ANA e Portal Brasil Agroecológico}

Em suas diferentes configurações sociais e históricas, observa-se que a agroecologia possui definições distintas, a considerar agroecossistemas, sistemas e regimes alimentares, políticas públicas e disciplinas científicas. Instituições e organizações denotam à agroecologia condições conceituais distintas, variando conforme os propósitos e entendimentos dessas organizações e entidades, em que a referência primordial para a existência dos respectivos sites ora está voltada para a divulgação acadêmica e articulação de congressos, ora para movimentos sociais e desenvolvimento de políticas públicas.

Nos próximos parágrafos, serão relatados alguns dos levantamentos realizados em alguns sites que representam no período histórico mais recente grupos de pessoas em torno da Agroecologia no Brasil.

Conforme exposto em relação ao conhecimento científico e suas metodologias, a agroecologia por vezes abrange áreas que vão além do que se estipula como convencional, chegando ao "alternativo", o que torna incitante a busca problemática pelos motivos que levam a essas peculiaridades. Em cada uma das referências propostas a seguir, buscou-se identificar ao menos em linhas gerais e conforme consta nos respectivos endereços eletrônicos, como 
essas entidades compreendem a ciência no geral ou a ciência agroecológica em seu meio.

O objetivo deste subtítulo é manifestar complemento ao que foi proposto em assunto anterior, no que concerne ao antagonismo encontrado muitas vezes entre o que se diz como alternativo e o que se convenciona como científico. Iniciando pelo IBA e desenvolvendo as leituras sobre o que os sites dispõem até o portal do governo sobre agroecologia, obteve-se um panorama bem explanativo sobre o que cada uma dessas instituições entende por uma agroecologia sustentada por um cunho científico.

\subsection{Instituto Brasileiro de Agroecologia (IBA)}

O IBA foi fundado em 2018 e, na página inicial do site do instituto, a própria frase do slogan já deixa clara a identificação com o campo científico apesar de aparentemente contracenar com a prática convencional da agropecuária, o que não é comum de se ver em ambientes em que a agroecologia impera. A frase constante é "O nosso foco é científico e voltado para o Agronegócio profissional" [34].

Existem muitas maneiras de se discorrer sobre um mesmo tema no que concerne à agricultura e, no caso específico à agroecologia, então pode-se perceber que muitas das pessoas que sobrevivem do trabalho nas áreas rurais - por mais que o façam, a exemplo, em ambiente familiar, com produção orgânica e sem vínculos e amarras contratuais com as grandes marcas tendem a se considerar como parte do agronegócio, pois são indivíduos que se compreendem como produtores agrícolas (agro) e que sobrevivem de suas trocas, compras e vendas nesse meio (negócio).

Com esta justificativa, surgiu uma pequena problemática sobre o slogan do Instituto Brasileiro de Agroecologia, tal qual se o mesmo determina um apoio ou trabalho conjunto com os ideais da agroecologia sobre os meios convencionais da prática comercial agrícola, ou se o próprio instituto se apercebeu da importância que o termo convencional parece denotar na sociedade como um todo, e acabou vinculando-o com o propósito de abrangência de público, procurando evitar confusões decorrentes da nomenclatura comentada. 
O IBA possui em seu site algumas fotografias e textos explicativos referentes aos objetivos a que se propõe. Dentre as imagens, podemos ver a de uma máquina agrícola em meio a uma monocultura de tamanho considerável, o que remete à multiplicidade de ideias no que diz respeito aos entendimentos sobre o termo "agroecologia" como ciência do campo da complexidade, vide comparativamente orientação mais determinada por policultivos, a qual contraria o que se apresenta na fotografia em questão.

Dentre os objetivos propostos pelo instituto, consta como primeiro deles o de

promover a construção e o desenvolvimento de um novo modelo técnico-comercial para o agronegócio, compatível com os valores humanos e ambientais, e com os desejos da sociedade por mais saúde e qualidade de vida [35].

O diferencial representado pelo IBA se encontra na vinculação desse novo modelo ao agronegócio já existente, enquanto que por um outro lado, podemos comumente observar movimentos e disciplinas da agroecologia em defesa antagônica ao da agricultura convencional. Como missão, o instituto esclarece a busca para "viabilizar a implantação de sistemas agroecológicos de produção de alimentos em larga escala no Brasil (...)", o que remete a uma das principais críticas que os defensores da agricultura convencional costumam dirigir à agroecologia, mesmo que de maneira equivocada: a de que a produção orgânica ou agroecológica não poderia ser feita em larga escala e, portanto, não seria capaz de alimentar o mundo [36]. Dessa forma e sob análise do objetivo e da missão identificados no site, pode-se ficar a par de como a agroecologia pode ser complexa e plural em seus valores e atribuições práticas, mas não por isso perde a característica de ser objetiva e precisa em muitas de suas atividades.

Sob uma perspectiva mais qualitativa de estudo do IBA, a caracterização científica se torna mais aparente quando da demonstração de projetos como o de contabilidade ambiental na produção de alimentos. Neste, o IBA realiza um registro anual (com duração de 10 anos) de parâmetros físicos, químicos e biológicos que apontem as consequências do sistema de produção utilizado. 
$\mathrm{Na}$ avaliação, constam itens como degradação, intoxicação, recuperação e desintoxicação do agroecossistema avaliado ao longo do projeto.

Um outro projeto é mais específico na área de cuidados com os alimentos, no que diz respeito à adubação e respectivos retornos benéficos à saúde humana no posterior consumo de hortaliças, principalmente. O objetivo é a produção de alimentos nutricionalmente mais ricos, e o processo se dá por meio de, na prática, realizar um comparativo entre o sistema de adubação que já era utilizado convencionalmente pelo produtor versus uma adubação alternativa do instituto, composto por pós de rocha, compostos orgânicos e bioestimulantes. O pó de rocha tem sido uma alternativa interessante em muitas regiões, devido ao fato de que o solo brasileiro tende a apresentar dificuldade na oferta de fósforo, macronutriente essencial para o desenvolvimento das plantas.

Assim, obtemos deste projeto do instituto um contraste referencial entre a ciência agrícola convencional, detentora de fertilizantes altamente solúveis e de ação rápida para a agricultura convencional, e entre as rochas moídas determinadas como fertilizantes alternativos e de ação mais lenta.

\subsection{Associação Brasileira de Agroecologia (ABA)}

A ABA foi fundada em 2004, e realiza e apoia ações dedicadas à construção do conhecimento agroecológico, conforme especificado em seu site. A fim de ter um alcance maior nesse apoio, a associação possui Grupos de Trabalho (GT) que realizam atividades em nome da $A B A$, e são em número de oito: GT Agrotóxicos e Transgênicos; GT Campesinato e Soberania Alimentar; GT Construção do Conhecimento Agroecológico; GT Cultura e Comunicação; GT Educação em Agroecologia; GT Gênero; GT Juventudes e GT Saúde.

A agroecologia, para a $A B A$, é entendida como:

enfoque científico, teórico, prático e metodológico, com base em diversas áreas do conhecimento, que se propõe a estudar processos de desenvolvimento sob uma perspectiva ecológica e sociocultural e, a partir de um enfoque sistêmico (...) apoiar a 
transição dos modelos convencionais de agricultura e de desenvolvimento rural para estilos de agricultura e de desenvolvimento rural sustentável [37].

De início, percebemos algumas peculiaridades em comparação com o Instituto Brasileiro de Agroecologia. Na ABA, o enfoque sobre a agroecologia se aproxima da conceituação condizente com o artigo de Alexander Wezel et al, sendo uma ciência, um movimento e uma prática. Isso pode ser observado justamente por meio dos Grupos de Trabalho relatados no site, os quais compõem uma variedade de temas que, dentro do estudo agroecológico, se interligam cobrindo a descrição final da $A B A$, tal qual "apoiar a transição dos modelos convencionais (...) para estilos de agricultura (...) sustentável."

No IBA, há um foco mais tecnológico-comercial, com vistas ao desenvolvimento de uma agricultura ecológica potencialmente viável. Ambas desafiam-se com propostas que são deveras arrojadas e determinadas: ora buscando uma integração holística por meio de um caleidoscópio de informações, ora determinada sobre um eixo científico e prático destinado a aplicação de conhecimento para a tecnologia agrícola, essencialmente biológica e sustentada por uma esfera agronômica de entendimento.

Com um enfoque mais voltado para o científico e acadêmico, a Associação Brasileira de Agroecologia desenvolve, desde 2006, a editoração da Revista Brasileira de Agroecologia [38], periódico online destinado à divulgação de trabalhos sobre agroecologia e áreas afins. Ainda conforme informações do site, em parceria com a Articulação Nacional de Agroecologia (ANA) a ABA mantém o Agroecologia em Rede, o qual se caracteriza como um canal público e que possui um cadastro de 730 experiências brasileiras e latino-americanas em agroecologia, além de 432 pesquisas. Além do Agroecologia em Rede, a ABA também desenvolve, a cada dois anos, 0 Congresso Brasileiro de Agroecologia (CBA), descrito mais adiante.

O aporte científico da ABA se situa, portanto, na publicação e divulgação de eventos que direcionem ações sobre a pesquisa em agroecologia. Isso é realizado de variadas formas, sob diferentes aspectos, como foi possível de ser observado propriamente por meio das divisões de suas atividades, pareamentos com outras entidades e seus GT's. 


\subsection{Congresso Brasileiro de Agroecologia (CBA)}

O CBA iniciou suas atividades em 2003, um ano antes da fundação oficial da $A B A$, associação atualmente responsável pela realização dos congressos que ocorrem a cada dois anos. De início, o Congresso Brasileiro de Agroecologia possuía como foco um rol de atividades voltadas à valorização da agroecologia como ciência. Porém, atualmente se autodefine como um "verdadeiro espaço de diálogo entre os conhecimentos científicos e práticos", tendo um direcionamento mais atencioso aos trabalhos envolvendo a agricultura familiar e camponesa [39].

A ciência, para o CBA, é compreendida como um diálogo de saberes, sendo a sua construção um processo coletivo apresentado na forma de desafio, por entenderem que esse diálogo científico engloba também ideias sobre a arte e a soberania dos povos, sendo que a edição mais recente do evento (realizada entre os dias 4 e 7 de novembro de 2019) foi intitulada Ecologia de Saberes: Ciência, Cultura e Arte na Democratização dos Sistemas Agroalimentares. O endereço eletrônico também indica ser o CBA um

catalisador de processos participativos e de amplo diálogo entre sociedade civil organizada, academia e poder público, em torno deste tema altamente estratégico [40].

Podemos identificar uma gradual mudança no foco do CBA quando comparamos as suas atividades com as atividades da ABA (não visando uma aproximação como sendo decorrente da outra, mas apenas um comparativo acerca da leitura científica e prática de ambas). A ABA divulga e realiza ações envolvendo a agroecologia como ciência, movimento social e prática agrícola. O CBA, iniciado um ano antes da fundação da ABA, era um meio divulgador da agroecologia como ciência. Isso pode ser observado até no documento que discorre sobre a organização, o histórico e o objetivo do primeiro congresso realizado, o qual explicita ser o CBA um espaço específico para apresentação de trabalhos científicos sobre Agroecologia, após uma série de eventos da Emater/RS de 1999 a 2002, que culminou com a criação do evento [41].

Posteriormente, o CBA foi incorporando outros elementos em seus lançamentos e, hoje, segue um modelo semelhante ao da Associação 
Brasileira de Agroecologia, tal qual a divulgação e realização de trabalhos sobre a agroecologia como ciência, movimento e prática. A tabela a seguir sintetiza essa variação e multiplicidade temática, contendo os títulos dos eventos já realizados desde sua fundação, além da movimentação pautada sob as condições de participantes inscritos e trabalhos apresentados:

Tabela 1. Eventos do CBA e seus respectivos temas (2003-2019).

\begin{tabular}{|c|c|c|c|}
\hline & TEMA & $\begin{array}{r}\text { PARTICIPANTE } \\
\text { S INSCRITOS }\end{array}$ & $\begin{array}{c}\text { TRABALHOS } \\
\text { APRESENTADOS }\end{array}$ \\
\hline $\begin{array}{l}\text { I CBA (1) } \\
\text { (2003) } \\
\text { Porto Alegre } \\
\text { (RS) }\end{array}$ & $\begin{array}{c}\text { Conquistando a } \\
\text { Soberania } \\
\text { Alimentar }\end{array}$ & 3.366 & 386 \\
\hline $\begin{array}{l}\text { II CBA (2) } \\
\text { (2004) } \\
\text { Porto Alegre } \\
\text { (RS) }\end{array}$ & - & 3.021 & 439 \\
\hline $\begin{array}{l}\text { III CBA } \\
\text { (2005) } \\
\text { Florianópolis } \\
\text { (SC) }\end{array}$ & \begin{tabular}{l}
\multicolumn{1}{c}{ Sociedade } \\
construindo \\
conhecimentos \\
para a vida
\end{tabular} & 2.500 & 513 \\
\hline $\begin{array}{l}\text { IV CBA } \\
(2006) \\
\text { Belo } \\
\text { Horizonte } \\
\text { (MG) }\end{array}$ & $\begin{array}{l}\text { Construindo } \\
\text { Horizont } \\
\text { es } \\
\text { Sustentá } \\
\text { veis } \\
\end{array}$ & 1.340 & 429 \\
\hline $\begin{array}{l}\text { V CBA } \\
\text { (2007) } \\
\text { Guarapari } \\
\text { (ES) }\end{array}$ & $\begin{array}{c}\text { Agroecologia e } \\
\text { Territórios } \\
\text { Sustentáveis }\end{array}$ & 1.505 & 436 \\
\hline $\begin{array}{l}\text { VI CBA (3) } \\
\text { (2009) } \\
\text { Curitiba } \\
\text { (PR) }\end{array}$ & $\begin{array}{c}\text { Agricultura } \\
\text { Familiar e } \\
\text { Camponesa - } \\
\text { experiências } \\
\text { passadas e } \\
\text { presentes } \\
\text { construindo um } \\
\text { futuro } \\
\text { sustentável }\end{array}$ & $\begin{array}{c}4.000 \\
\text { (número } \\
\text { aproximad } \\
\text { o) }\end{array}$ & 1.086 \\
\hline $\begin{array}{l}\text { VII CBA } \\
\text { (2011) } \\
\text { Fortaleza } \\
\text { (CE) }\end{array}$ & $\begin{array}{c}\text { Ética na Ciência: } \\
\text { Agroecologia como } \\
\text { paradigma para o } \\
\text { desenvolvimento } \\
\text { rural }\end{array}$ & - & - \\
\hline
\end{tabular}




\begin{tabular}{|c|c|c|c|}
\hline $\begin{array}{l}\text { VIII CBA (4) } \\
(2013) \\
\text { Porto Alegre } \\
\text { (RS) }\end{array}$ & $\begin{array}{l}\text { Cuidando da Saúde } \\
\text { do Planeta }\end{array}$ & 4.448 & - \\
\hline $\begin{array}{l}\text { IX CBA (5) } \\
(2015) \\
\text { Belém (PA) }\end{array}$ & $\begin{array}{lr}\text { Diversidade } & \text { e } \\
\text { Soberania } & \text { na } \\
\text { Construção } & \text { do } \\
\text { Bem Viver } & \end{array}$ & - & - \\
\hline $\begin{array}{l}\text { X CBA (6) } \\
(2017) \\
\text { Brasília (DF) }\end{array}$ & $\begin{array}{l}\text { Agroecologia na } \\
\text { Transformação } \\
\text { dos Sistemas } \\
\text { Agroalimentares } \\
\text { na América } \\
\text { Latina: Memórias, } \\
\text { Saberes e } \\
\text { Caminhos para o } \\
\text { Bem Viver }\end{array}$ & 5.534 & 1.900 \\
\hline $\begin{array}{l}\text { XI CBA } \\
\text { (2019) } \\
\text { São } \\
\text { Cristóvão } \\
\text { (SE) }\end{array}$ & $\begin{array}{c}\text { Ecologia de } \\
\text { Saberes: Ciência, } \\
\text { Cultura e Arte na } \\
\text { Democratização } \\
\text { dos Sistemas } \\
\text { Agroalimentares }\end{array}$ & - & - \\
\hline
\end{tabular}

(1) Evento conjunto: IV Seminário Internacional sobre Agroecologia;

(2) Eventos conjuntos: V Seminário Internacional sobre Agroecologia e VI Seminário Estadual sobre Agroecologia;

(3) Evento conjunto: II Congresso Latino Americano de Agroecologia (SOCLA);

(4) Eventos conjuntos: XIII Seminário Estadual sobre Agroecologia, XII Seminário Internacional sobre Agroecologia e V Encontro Nacional de Grupos de Agroecologia;

(5) Eventos conjuntos: IV Seminário Estadual de Agroecologia e VII Encontro Nacional de Grupos de Agroecologia;

(6) Eventos conjuntos: VI Congresso Latino Americano de Agroecologia (SOCLA) e V Seminário de Agroecologia do Distrito Federal e Entorno.

Fonte: https://aba-agroecologia.org.br/cba/. Algumas referências não encontradas no endereço eletrônico desta fonte foram encontradas em sites paralelos aos do respectivo evento. 


\subsection{Assessoria e Serviços a Projetos em Agricultura Alternativa (AS-PTA}

\section{Agricultura Familiar e Agroecologia)}

A AS-PTA Agricultura Familiar e Agroecologia é uma associação atuante desde 1983, com vistas a promover o desenvolvimento rural sustentável no Brasil. Do período de sua fundação até os dias atuais, predominantemente a associação desenvolveu atividades com redes da sociedade civil, articulando movimentos, eventos e ações que procuravam influenciar a "elaboração, implantação e monitoramento de políticas públicas", conforme texto disponível no seu endereço eletrônico [42]. Digno de nota na atuação da entidade é a publicação do livro do agrônomo chileno e professor da Universidade da Califórnia, Miguel Altieri (“Agroecologia: bases científicas para uma agricultura sustentável"), que muito vem influenciando a disseminação das ideias e os contornos dessas ideias no campo agroecológico brasileiro [43].

Em se tratando de estratégias de trabalho, a AS-PTA desenvolve planos trienais, sendo que o mais antigo deles disponibilizado no site é o "Plano Trienal 1999-2001", no qual consta registro sobre ser o Centro de Documentação (CD) da AS-PTA a "mais completa fonte nacional de referências sobre desenvolvimento rural sustentável e agroecologia" [44]. Em sua página 13, é possível perceber uma relação de conflito analisada pela instituição no que diz respeito a uma confusão no seio da Embrapa (Empresa Brasileira de Pesquisa Agropecuária). Afirma-se existir uma dicotomia em discursos e programas em que se considera a "pesquisa para o agronegócio" uma oposição à "pesquisa social", sendo que deveria existir uma análise muito mais ampla entre elas, sem necessitar da divisão entre uma visão econômica e uma visão sociocultural. Esse problema levantado implica diretamente no que a associação buscava no primeiro plano trienal como área de interesse científico e técnico, explicitando que

...para influenciar os pesquisadores (e o sistema de pesquisa) é inútil prender-se a um interminável debate de ideias no seio das instituições de pesquisa. Ao contrário, devemos trazê-los para o "nosso campo", ou seja: sistematizar perguntas a serem colocadas à pesquisa e formular projetos em parceria para 
responder a essas perguntas, discutindo a partir daí concepções sobre o papel da ciência e do conhecimento (...) [45].

Concernente a esses debates que deveriam ser trazidos para o meio de pesquisa, um de seus objetivos de longo prazo se apresenta no mesmo documento: uma integração de conhecimentos em agronomia e ciências afins para o paradigma agroecológico, se fazendo necessária uma alteração destas ciências "tanto ao nível técnico como universitário" [46].

Um complemento na forma de ação estratégica a essa possível alteração das ciências é encontrada no "Plano Trienal 2002-2004", o qual referencia como um dos objetivos a "elaboração de um catálogo de instituições privadas e públicas de pesquisa e estudos nas áreas da ciência agrícola" [47]. No "Plano Trienal 2005-2007" consta registro de avanços no mundo acadêmico. Divulgase que:

A pesquisa em agroecologia vem sendo assumida por um número cada vez maior de profissionais vinculados a instituições oficiais. Embora o paradigma agroecológico ainda não oriente explicitamente o enfoque e a organização institucional de empresas de pesquisa e universidades públicas, a multiplicação dessas iniciativas individuais ou de pequenos grupos é reveladora da existência de um movimento de transformação (...) [48].

No "Plano Trienal 2008-2010", o resultado progressivo do trabalho da ASPTA pode ser observado no âmbito do projeto de institucionalização da agroecologia na EMBRAPA, registrando-se em texto do plano que a associação esteve representada nesta empresa no Conselho Assessor Nacional Externo, de onde pôde realizar proposições no que se refere a diretrizes agroecológicas, com projetos de pesquisa de comunidades de agricultores familiares [49]. 


\subsection{Articulação Nacional de Agroecologia (ANA)}

É um espaço que une redes, movimentos sociais e organizações da sociedade civil brasileira com fins de fortalecer a agroecologia, a produção familiar e o desdobramento de ações sustentáveis para o desenvolvimento rural [50]. Foi constituída em 2002 e, de acordo com as informações do seu site atualizadas em 31 de julho de 2018, realizou quatro Encontros Nacionais de Agroecologia (ENAs), sendo que o mais recente deles, realizado em 2018, foi convocado por 47 redes, organizações e movimentos da sociedade civil, congregando participação de cerca de 3.000 pessoas. Os ENAs constituem a principal organização para discussão de estratégias políticas da Articulação Nacional de Agroecologia, sendo seu papel primordial o de construir "unidade política para incidência de diálogo entre o governo e a sociedade" [51]. Dessa forma, a principal determinação da ANA no campo agroecológico se apresenta como uma organização conjunta de ações voltadas para a política.

$\mathrm{Na}$ página inicial de seu endereço eletrônico, possui em seu menu horizontal fixo o item "Temas prioritários". Levando o cursor do mouse por sobre este item, temos acesso aos links "Biodiversidade", "Soberania e Segurança Alimentar", "Financiamento", "Mulheres e agroecologia", "Políticas Públicas com enfoque agroecológico", "Agroenergia e Agroecologia" e "Marco Legal de Financiamento Público às Organizações da Sociedade Civil", o que já demonstra a amplitude de informações a qual temos acesso sobre uma mesma fonte.

Assim como a Associação Brasileira de Agroecologia, a ANA possui Grupos de Trabalho (GT), além dos denominados Coletivos, sendo esses dois, espaços de "intercâmbio de experiências e de formulação de propostas e negociação de políticas públicas", e são ambos abertos a interessados para as suas composições. Estão ativos os GT's "Biodiversidade" e "Mulheres e Ater" (Assistência Técnica e Extensão Rural), além dos Coletivos "Agricultura Urbana" e "Comunicadores".

A ANA também possui um sistema público de informações online denominado "Agroecologia em Rede", no qual é possível um indivíduo se cadastrar, ler e realizar comentários a respeito de práticas, grupos, reuniões, redes, informações e experiências relacionadas à Agroecologia. O AeR, como ficou conhecido, surgiu no ano 2000 em parceria com a AS-PTA e a 
Universidade Federal Rural de Pernambuco (UFRPE), tendo como atividade primordial o lançamento de boletins informativos de um projeto sobre plantas nativas do nordeste, e somente mais tarde migrando para o propósito mais amplo do AeR, de registro das experiências amplas em agroecologia.

\subsection{Portal Brasil Agroecológico}

$\mathrm{Na}$ busca por referências da agroecologia, optou-se pela escolha da última aqui listada como sendo representante governamental, vinculada a planos e projetos do Governo Federal e com suas bases institucionalizadas a partir de leis federais e, como portal online, fundado em 2017 [52].

Essa decisão se tornou pertinente a partir do momento em que se percebeu que é possível levantar uma relação de proximidade entre o IBA, a ABA, o CBA, a AS-PTA e a ANA, no que diz respeito às suas ações e projetos: muitos dos eventos realizados por uma das entidades descritas é apoiada por uma outra ou mais delas, sendo clara a relação de reciprocidade, auxílio e reconhecimento mesmo que com divergências de opiniões, mesmo que com eixos e objetos de estudos distintos, como no exemplo observado do IBA. Importante destacar que o trabalho conjunto realizado ao longo desses anos pelas entidades citadas e por outras que não foram elencadas para esta análise, foi responsável ou está sendo, direta ou indiretamente, por algumas mudanças configuradas dentro da esfera das políticas públicas e da produção acadêmica, como exemplo: na certificação de produtos orgânicos, nas políticas sobre a agricultura familiar, nas pesquisas sobre a redução de impacto negativo da agricultura na biosfera, no desenvolvimento de cursos técnicos e de ensino superior e publicações científicas na área de Agroecologia.

Em suma, tratar por último do Portal Brasil Agroecológico é praticamente tratar dos resultados da influência de atuação das cinco entidades anteriormente identificadas. De acordo com o seu próprio site:

o portal surge com o ideal de dar visibilidade aos avanços da Política Nacional de Agroecologia e Produção Orgânica - Pnapo e ao Plano Nacional de Agroecologia e Produção Orgânica Planapo, possibilitando a visualização dos resultados gerados no cotidiano da política. É um espaço de importante valor, 
representação simbólica e afirmação da relevância quanto à continuidade de políticas públicas para a agroecologia e produção orgânica [53].

O PLANAPO em referência dá nome ao portal (o Plano é conhecido como "Brasil Agroecológico") e foi elaborado e é executado pela Câmara Interministerial de Agroecologia e Produção Orgânica (CIAPO), a qual articula diferentes entidades do Poder Executivo Federal. A relação entre o governo e a sociedade civil se dá por meio da Comissão Nacional de Agroecologia e Produção Orgânica (CNAPO), desenvolvendo um espaço de discussões de onde se iniciam os planos de controle social do PLANAPO. A construção do portal, em si, partiu da Câmara (a CIAPO).

A CIAPO foi criada pelo Decreto $n^{0}$ 7.794, de 20 de agosto de 2012, o qual institui a PNAPO [54]. É integrada por 9 ministérios e 6 autarquias convidadas, sendo que, de acordo com o site, o então Ministério do Desenvolvimento Agrário exercia função de Secretaria-Executiva. Já a CNAPO é composta por 14 representantes da sociedade civil e 14 representantes advindos de órgãos do Governo Federal.

O Instituto de Pesquisa Econômica Aplicada (IPEA) publica as ações desenvolvidas pelas entidades vinculadas ao Portal Brasil Agroecológico, demonstrando em quais áreas, sob quais condições e quais dados quantitativos e qualitativos podem ser tomadas por meio dos programas e avanços em pesquisas desenvolvidas. Um dos principais documentos é a "Avaliação do Plano Nacional de Agroecologia e Produção Orgânica - Planapo 2016-2019", o qual traduz as atividades mais recentes realizadas e a projeção futura de seus resultados por meio de linhas históricas e cronológicas [55].

As publicações sob modelos de cartilhas, documentos e outros envolvem questões pertinentes à agricultura familiar, comunidades indígenas, selo de qualidade para produtos orgânicos, projetos de plantio direto, cultivo orgânico de hortaliças, adubação organomineral, monitoramento de agrotóxicos na água, utilização de adubação verde, dentre outros.

A tabela a seguir resume as informações e direcionamentos relativos às instituições registradas até aqui. É pertinente a lembrança de que tais informações foram atribuídas com base na interpretação advinda de uma 
leitura direta, a qual toma por base as informações estritamente contidas nos endereços eletrônicos das respectivas instituições, pesquisadas e revisadas em 2019 e 2020.

Tabela 2. Instituições e suas interpretações sobre a agroecologia.

\begin{tabular}{|c|c|c|}
\hline $\begin{array}{l}\text { INSTITUIÇÃO / } \\
\text { FUNDAÇÃO }\end{array}$ & APRESENTAÇÃO & $\begin{array}{l}\text { ATUAÇÃO E } \\
\text { ENFOQUE DA } \\
\text { AGROECOLOGIA }\end{array}$ \\
\hline $\begin{array}{l}\text { IBA } \quad \text { Instituto } \\
\text { Brasileiro de } \\
\text { Agroecologia / } \\
2018\end{array}$ & $\begin{array}{cl}\text { Foco } & \text { científico voltado } \\
& \text { para } \\
& \text { Agronegócio }\end{array}$ & $\begin{array}{c}\text { Modelo técnico- } \\
\text { comercial compatível } \\
\text { com valores humanos } \\
\text { e ambientais }\end{array}$ \\
\hline $\begin{array}{l}\text { ABA - Associação } \\
\text { Brasileira de } \\
\text { Agroecologia I } \\
2004\end{array}$ & $\begin{array}{c}\text { Construção } \\
\text { conhecimento } \\
\text { agroecológico }\end{array}$ & $\begin{array}{l}\text { Enfoque } \\
\text { teórico, prático } \\
\text { e } \\
\text { metodológico; } \\
\text { perspectiva } \\
\text { ecológica e } \\
\text { sociocultural }\end{array}$ \\
\hline $\begin{array}{l}\text { CBA - Congresso } \\
\text { Brasileiro de } \\
\text { Agroecologia I } \\
2003\end{array}$ & $\begin{array}{l}\text { Espaço de diálogo } \\
\text { entre os } \\
\text { conhecimentos } \\
\text { científicos e práticos }\end{array}$ & $\begin{array}{c}\text { De início, foco em } \\
\text { pesquisas técnicas } \\
\text { baseadas em projetos } \\
\text { da Emater/RS. Hoje, } \\
\text { diálogo de saberes } \\
\text { que engloba a arte e } \\
\text { conhecimento popular }\end{array}$ \\
\hline $\begin{array}{c}\text { AS-PTA - Assessoria } \\
\text { e Serviços a Projetos } \\
\text { em Agricultura } \\
\text { Alternativa } \\
\text { / } 1983\end{array}$ & $\begin{array}{l}\text { Desenvolvimento Rural } \\
\text { Sustentável por meio } \\
\text { de redes com a } \\
\text { sociedade civil }\end{array}$ & $\begin{array}{c}\text { Elaboração, } \\
\text { monitoramento e } \\
\text { implementação de } \\
\text { políticas públicas }\end{array}$ \\
\hline $\begin{array}{l}\text { ANA - Articulação } \\
\text { Nacional de } \\
\text { Agroecologia I } \\
2002\end{array}$ & $\begin{array}{l}\text { Encontros nacionais } \\
\text { para discussão de } \\
\text { estratégias políticas }\end{array}$ & $\begin{array}{c}\text { Unidade política para } \\
\text { incidência de diálogo } \\
\text { entre o governo e a } \\
\text { sociedade }\end{array}$ \\
\hline $\begin{array}{c}\text { Portal Brasil } \\
\text { Agroecológico / } 2017\end{array}$ & $\begin{array}{l}\text { Demonstração dos } \\
\text { avanços da Política } \\
\text { Nacional de Agroecologia } \\
\text { e Produção Orgânica }\end{array}$ & $\begin{array}{l}\text { Representatividade } \\
\text { simbólica sobre as } \\
\text { políticas públicas } \\
\text { para a agroecologia e } \\
\text { a produção orgânica }\end{array}$ \\
\hline
\end{tabular}




\section{Conclusão}

O que se pode perceber por essa breve exposição é como a Agroecologia passou por uma transformação no que se refere ao seu entendimento desde a década de 1970 no Brasil, passando a se conectar a uma pauta mais ampla de reivindicações sociais e políticas, e com uma tendência de menor ligação com as correntes esotéricas de pensamento. A partir da década de 1990 é visível a institucionalização e a incorporação do ideal de uma agricultura mais sustentável nas agendas de ONGs, órgãos governamentais e nas próprias universidades. Ou seja, cada vez mais a Agroecologia vai deixando de ser o alternativo que era até a década de 1980, mas sendo incorporado na agenda da sustentabilidade, embora muitas vezes de uma forma apenas discursiva, sem o apoio necessário para a implantação efetiva em escala massiva. Pessoas emblemáticas da Agroecologia como José Lutzemberger e Ana Primavesi vão ficando para trás na história, mas muitos dos seus ideias continuam sendo estudados e refletidos nas práticas correntes. Há que se considerar que a própria agricultura convencional e seus defensores não passaram imunes por esses desenvolvimentos, considerando o avanço nas legislações de controles de agrotóxicos nos anos 80 e recomendações de práticas agronômicas menos impactantes como o manejo integrado de pragas e o controle biológico. Acreditamos que o futuro da Agroecologia no Brasil nesse século XXI dependerá de um investimento e uma ênfase cada vez maior na pesquisa científica e na formação de técnicos aptos a trabalhar com os agricultores, buscando soluções que atendam as demandas de um país cada vez mais povoado e com papel importante no abastecimento alimentar mundial, mas que precisa cuidar urgentemente dos seus preciosos biomas e ainda contribuir no concerto de nações para a mitigação climática.

\section{Referências}

[1] Pádua J.A. Herança romântica e ecologismo contemporâneo - Existe um vínculo histórico? Herança Romântica. Varia História 2005; 21(33): 58-75. https://doi.org/10.1590/S0104-87752005000100004.

[2] Viola E.J. O movimento ecológico no Brasil (1974-1986): do ambientalismo à ecopolítica. Revista Brasileira de Ciências Sociais 1987; 1 (3): 1-21. http://anpocs.com/images/stories/RBCS/03/rbcs03_01.pdf. 
[3] Biblioteca Nacional Digital. http://bndigital.bn.gov.br/hemeroteca-digital/. Acesso em: 01 de fev. 2021.

[4] Pararraios A. $1^{\circ}$ Comício Cósmico do Planalto Central. Correio Brasiliense (DF), Brasília, 13/08/1983, Seção Viva Alternativa, p. 6. In: Biblioteca Nacional. Hemeroteca Digital da Biblioteca Nacional. https://rebrand.ly/f6e84. Acesso em: 01 de fev. 2021.

[5] Biblioteca Nacional Digital. Hemeroteca Digital da Biblioteca Nacional. Ciências formula novas matérias. Diário do Paraná: Órgão dos Diários Associados (PR), Curitiba, 13/07/1974, Seção Local, p. 6. Disponível em: https://rebrand.ly/t2mnl. Acesso em: 11 de mar. 2021.

[6] Biblioteca Nacional Digital. Governo copia e estimula a agricultura alternativa. Correio Braziliense (DF). Brasília, 01 de ago de 1985, Ed. 8157. https://rebrand.ly/d8033. (ocorrência 16/106). Acesso em: 11 de mar. 2021.

[7] Biblioteca Nacional Digital. Pararraios, A. Valdo França: agricultura como alternativa de sobrevivência. Correio Braziliense (DF). Brasília, 07 de jan de 1983, Ed. 07254, Seção Viva Alternativa. Coluna Agronomia. https://rebrand.ly/a8zve. (ocorrência 3/106). Acesso em: 11 de mar. 2021.

[8] Biblioteca Nacional Digital. Congresso discute a reforma agrária. Correio Braziliense (DF). Brasília, 30 de jul de 1985, Ed.8155. https://rebrand.ly/9njez. (ocorrência 15/106). Acesso em: 11 de mar. 2021.

[9] Biblioteca Nacional Digital. Engenheiro quer agricultura sem sotaques. Correio de Notícias (PR). Curitiba, 23 de mar de 1985, Ed. 1125, p. 8, Seção Geral. https://rebrand.ly/7zz0o. (ocorrência 14/50). Acesso em: 11 de mar. 2021.

[10] Biblioteca Nacional Digital. Terra Viva, programa do Banestado financia agricultura alternativa. Correio de Notícias: a serviço do Paraná (PR), 22/10/1991, A-3. https://rebrand.ly/c49hs. Acesso em: 11 de mar. 2021.

[11] Kosseleck R. Estudos Históricos, Rio de Janeiro, 1992; 5 (10): 134-146. palestra transcrita, traduzida e editada por Manoel Luis Salgado Guimarães.

[12] Delumeau J. História do Medo no Ocidente: 1300 - 1800. São Paulo: Companhia das Letras; 1989.

[13] Greene W. Fotos: Peter Simon. Os Novos Alquimistas: vivendo em paz com a natureza - sem usar máquinas ou técnicas modernas. Jornal do Brasil (RJ). Rio de Janeiro, 1976, Ed. 185. p. 26-28. In: Biblioteca Nacional. 
Hemeroteca Digital da Biblioteca Nacional. https://rebrand.ly/53gd1. Acesso em: 18 de fev. 2020.

[14] Barton G. The Global History of Organic Farming. United Kingdom: Oxford University Press; 2018. p.1.

[15] Navarro Z. Agroecologia: as coisas em seu lugar (A agronomia brasileira visita a terra dos duendes). COLÓQUIO - Revista do Desenvolvimento Regional - Faccat - 2013; $10 \quad$ (1) jan./jun.: 11-45. https://doi.org/10.26767/coloquio.v10i1.23.

[16] Kuhn T.S. A Estrutura das Revoluções Científicas. São Paulo: Perspectiva; 2018.

[17] Pinker S. O Novo lluminismo: em defesa da razão, da ciência e do humanismo. São Paulo: Companhia das Letras; 2018. p.463.

[18] Weinberg S. Para explicar o mundo: a descoberta da ciência moderna. São Paulo: Companhia das Letras; 2015.

[19] Popper K.R. A Lógica da Pesquisa Científica. 2 ed. São Paulo: Editora Cultrix; 2013.

[20] Idem. p.303- 304.

[21] Fereyabend P.K. Contra o método. 2 ed. São Paulo: Editora Unesp; 2011. p.60n e 195.

[22] Idem. p.21.

[23] Biblioteca Nacional. Hemeroteca Digital da Biblioteca Nacional. Agricultura: práticas alternativas. Correio de Notícias (PR), 09/04/1985. Seção Geral, p.13. Disponível em: https://rebrand.ly/b9xlb0f. Ocorrência 15/50 na Hemeroteca Digital. Acesso em: 18 de fev. 2020.

[24] Cardoso I.M. Entrevista concedida a Paulo Henrique Vailati. Laranjeiras do Sul - PR, 11 de Setembro de 2020.

[25] The Lancet. The end of homeopathy. The Lancet 2005; 366 (27) aug: 690. https://rebrand.ly/7kul2. Acesso em: 01 de fev. 2021.

[26] Associação Brasileira de Agricultura Biodinâmica (ABD). São Paulo. https://biodinamica.org.br/2/preparados-biodinamicos. Acesso em: 01 de fev. 2021.

[27] Wezel A. et al. Agroecology as a Science, a Movement and a Practice. A Review. Agronomy for Sustainable Development 2009. 29: 503-515. p.503. 10.1007/978-94-007-0394-0_3. 
[28] Khatounian C.A. Entrevista concedida a Paulo Henrique Vailati. Laranjeiras do Sul - PR, 22 de janeiro de 2020.

[29] Costa M.B.B. da. Entrevista concedida a Paulo Henrique Vailati. Laranjeiras do Sul - PR, 28 de novembro de 2019.

[30] Wezel A. et al. Ibid. p.3.

[31] Balla J.V.Q, Massukado L.M., Pimentel V.C. Panorama dos cursos de agroecologia no Brasil. Revista Brasileira de Agroecologia 2014; 9(2):3-14. p.5. http://revistas.aba-

agroecologia.org.br/index.php/rbagroecologia/article/view/15589.

[32] Brasil. Decreto $n^{0} 7.794$, de 20 de agosto de 2012. Institui a Política Nacional de Agroecologia e Produção Orgânica. Brasília, DF, ago 2012. https://rebrand.ly/cd9hm. Acesso em: 01 de fev. 2021.

[33] Wezel A., Soldat V. A quantitative and qualitative historical analysis of the scientific discipline of agroecology. International Journal of Agricultural Sustainability 2009; 7(1):3-18. 10.3763/ijas.2009.0400.

[34] Instituto Brasileiro de Agroecologia. https://www.iba.agr.br/quem-somos/. Acesso em: 01 de fev. 2021.

[35] Idem.

[36] Reganold J.P., Wachter J.M. Organic agriculture in the twenty-first century. Nature Plants 2016; Feb, 15221 (3):1-8. 10.1038/nplants.2015.221.

[37] Associação Brasileira de Agroecologia. https:/labaagroecologia.org.br/sobre-a-aba-agroecologia/sobre-a-aba/. Acesso em: 01 de fev. 2021.

[38] Revista Brasileira de Agroecologia. https://rebrand.ly/km8yr. Acesso em: 01 de fev. 2012.

[39] Congresso Brasileiro de Agroecologia. http://www.cbagroecologia.org.br/. Acesso em: 02 de fev. 2021.

[40] Disponível em: https://aba-agroecologia.org.br/cba/. Acesso em: 02 fev. 2021.

[41] Organização, histórico e objetivo do l Congresso Brasileiro de Agroecologia. Porto Alegre, 2003. Revista Brasileira de Agroecologia 2003; 1(1), p. 4. https://rebrand.ly/rlld6. Acesso em: 02 de fev. 2021.

[42] AS-PTA Agricultura Familiar e Agroecologia. http://aspta.org.br/. Acesso em: 02 de fev. 2021. 
[43] Altieri M. Agroecologia: bases científicas para uma agricultura sustentável. Guaíba: Agropecuária; 2002.

[44] AS-PTA Agricultura Familiar e Agroecologia. Plano Trienal 1999-2001. http://aspta.org.br/files/2011/01/AS-PTA-Plano- Trienal-1999-2001.pdf. p.19. Acesso em: 02 de fev. 2021.

[45] Idem. p.13.

[46] AS-PTA Agricultura Familiar e Agroecologia. Plano Trienal 1999-2001. p. 22 http://aspta.org.br/files/2011/01/AS-PTA-Plano- Trienal-1999-2001.pdf. Acesso em: 02 de fev. 2021.

[47] AS-PTA Agricultura Familiar e Agroecologia. Plano Trienal 2002-2004. p. 64. http://aspta.org.br/files/2011/01/AS-PTA-Plano- Trienal-2002-20041.pdf. Acesso em: 02 fev. 2021.

[48] AS-PTA Agricultura Familiar e Agroecologia. Plano Trienal 2005-2007. p. 14. http://aspta.org.br/files/2011/01/AS-PTA-Plano- Trienal-2005-2007.pdf. Acesso em: 02 de fev. 2021.

[49] AS-PTA Agricultura Familiar e Agroecologia. Plano Trienal 2008-2010. p.54. http://aspta.org.br/files/2011/01/AS-PTA-Plano- Trienal-2008-2010.pdf. Acesso em: 02 de fev. 2021.

[50] Articulação Nacional de Agroecologia. https://agroecologia.org.br/. Acesso em: 02 de fev. 2021.

[51] Disponível em: https://agroecologia.org.br/o-que-e-a-ana/. Acesso em: 02 de fev. 2021.

[52] Portal Brasil Agroecológico. http://agroecologia.gov.br/. Acesso em: 02 de fev. 2021.

[53] Disponível em: http://www.agroecologia.gov.br/quem-somos. Acesso em: 02 de fev. 2021.

[54] Brasil. Decreto $n^{0}$ 7.794, de 20 de agosto de 2012. Institui a Política Nacional de Agroecologia e Produção Orgânica. Brasília, DF, 20 ago 2012. https://rebrand.ly/cd9hm. Acesso em: 02 de fev. 2021.

[55] Instituto de Pesquisa Econômica Aplicada. Avaliação do Plano Nacional de Agroecologia e Produção Orgânica - Planapo 2016-2019. Ministério do Planejamento, Desenvolvimento e Gestão. Brasília. https://rebrand.ly/p8ikt. Acesso em: 02 de fev. 2021. 


\section{Autores}

Paulo Henrique Vailati, Miguel Mundstock Xavier de Carvalho

Programa de Pós-Graduação em Agroecologia e Desenvolvimento Rural Sustentável, Universidade Federal da Fronteira Sul (UFFS), Campus Laranjeiras do Sul, Paraná, Brasil.

* Autor para correspondência: miguelmxdecarvalho@gmail.com 